\title{
Superconducting Magnetic Energy Storage Unit for Damping Enhancement of a Wind Farm Generation System
}

\author{
E. Salih, S. Lachowicz, O. Bass, and D. Habibi
}

\begin{abstract}
A superconducting magnetic energy storage (SMES) system contains a high inducting coil and combines with power conversion system can act as a constant source of direct current. SMES unit connected to a power system is able to absorb and store both active and reactive power from this system and to inject these powers into the power system in the demand periods. These injected powers are controlled by changing both the duty cycle of the dc-dc chopper switches and its operation modes. This paper presents an efficient design based on an SMES unit controlled by the artificial neural network (ANN) to improve transient stability by regulating the dc link voltage and to damp the voltage and frequency fluctuations that are always associated with wind power generator. The authors propose interfacing the SMES between wind power farm and the power grid connected through the DC Link capacitor to rapidly stabilize the voltage and frequency fluctuations in the power system. The system behavior is tested with three different events for both voltage and frequency fluctuations of wind power generation with and without applying the SMES unit. The results show that both voltage and frequency stabilities are significantly increased when the SMES unit is applied in these three events.
\end{abstract}

Index Terms-Power stability, superconducting magnetic energy storage (SMES), transient, wind power generation.

\section{INTRODUCTION}

Recently, integration of wind power generation into grids has become one of the most important and fast growing electricity generation forms among the renewable energy sources [1]. However, wind power, which changes randomly and frequently, affects power system operation and leads to severe instability problems. This wind energy operation requires more development, so it will be more robust and have a higher efficiency conversion system to overcome these stability issues and to make the wind power generation more efficient and effective.

Today, all over the world, about 30,000 wind turbine generators have been operating in wind farm (WFs) as sources of energy. The induction generator (IG) is one type of wind generators employed in WFs. The IGs have some advantages over the other wind turbine types when they are used in WFs like the ability of a direct connection to a power grid, cost effectiveness, and robustness for variable-speed energy conversion systems. However, IG requires reactive power for magnetisation. The wind fluctuations over the WFs

Manuscript received May 28, 2014; revised November 1, 2014.

The authors are with the School of Engineering, Edith Cowan University, Joondalup, 6027 WA Australia (e-mail: esalih@our.ecu.edu.au, s.lachowicz@ecu.edu.au,o.bass@ecu.edu.au,d.habibi@ecu.edu.au). lead to variations in the generated active power of the wind IGs and to several disturbances in the absorbed reactive power and the voltage of the bus connected to the IGs and this affects power systems' stability. Hence, under the normal operating conditions controlling the power flow and voltage of a WF is generally required. For an effective and quick compensation of fluctuating components generated by a WF, an energy storage system is always combined with the wind farm generators. Various energy storage systems such as battery energy storage system (BESS) [2], [3], compressed air energy storage units (CAES) [4], and superconducting magnetic energy storage (SMES) units [5]-[7] may be linked to a WF to reduce the fluctuation in its generated power.

In this paper, we employ an SMES unit and a designed SMES damping controller as a control scheme to solve the inherent power-fluctuation problem of a WF effectively and simultaneously. The SMES unit contains a DC superconducting coil that can store and save a large amount of electric energy in the magnetic field. The main advantage of using an SMES unit is that both active and reactive power can be simultaneously controlled. An SMES absorbs or releases the active power to the low-loss superconducting coil, depending on the power requirements of the system. In addition, in SMES, the power conditioning system (PCS) is the interface unit that allows the effective connection to the power systems.

SMES systems were found in some previous research to be an effective stabilizer of power systems. For example, the experimental operation at Tacoma substation, Washington, where a 30-MJ SMES system was made for damping the oscillations observed on the 500-kV Pacific AC Intertie, showed that the stability limit of the Pacific AC Intertie from $2100 \mathrm{MW}$ to $2500 \mathrm{MW}$ can be increased by using the SMES In addition, an SMES can control the active and reactive power delivered to or received by tuning both the modulation index and the phase angle of its power converter [8]. In another study, the controlled SMES unit was found to be an effective device for stability enhancement of power systems [6]. Furthermore, the SMES unit with PI controllers [9], [10] and PID controllers [6], [11], [12] was developed to damp low-frequency oscillations of the studied systems. Moreover, as it is presented in [13], an SMES unit with a fuzzy controller was developed to enhance transient stability of a power system and the stability indices of the power system with the SMES unit and with a breaking resistor (BR) were compared.

Thus in the literature, many strategies have been used to increase power systems' stability by controlling SMESs; and because of the inherently nonlinear and variable structure of power systems, this non-linearity must be considered in 
designing a more effective SMES controller [14]. Therefore, we considered the neural network $(\mathrm{NN})$ as one of the artificial intelligent control techniques to build a nonlinear adaptive controller to control the power flow between the SMES and power system to improve its stability and enhance its performance. In this paper, we propose an application of the $\mathrm{NN}$ to control SMES for stabilization and damping voltage and frequency oscillations. Since NN will be used to control the system, back-propagation through time algorithm is chosen to cope with the continuous time dynamics [14]. In this study, the effects of both SMES and NN on power system stability are investigated. Furthermore, we determined the transient responses of the studied WF, subject to various disturbance conditions; and we present both steady-state results and transient performance of a large-scale WF based on an equivalent grid-connected IG under various wind speeds.
Our paper is organized as follows. Section II introduces the configuration and the employed mathematical models of the studied WF. Section III shows and compares transient responses of the studied WF with and without the proposed SMES unit linked to the designed damping controller under disturbance conditions. Specific conclusions of this paper are drawn in Section IV.

\section{CONFIGURATION OF THE DESIGNED SySTEM}

Fig. 1 shows the configuration of the studied WF containing the proposed SMES unit. A variable speed wind turbine is used to drive the wind induction generator (IG). The SMES unit is connected to the DC side of the wind farm through a dc-dc chopper. It is positioned as an interfaces device between the IG and a local load and the utility grid.

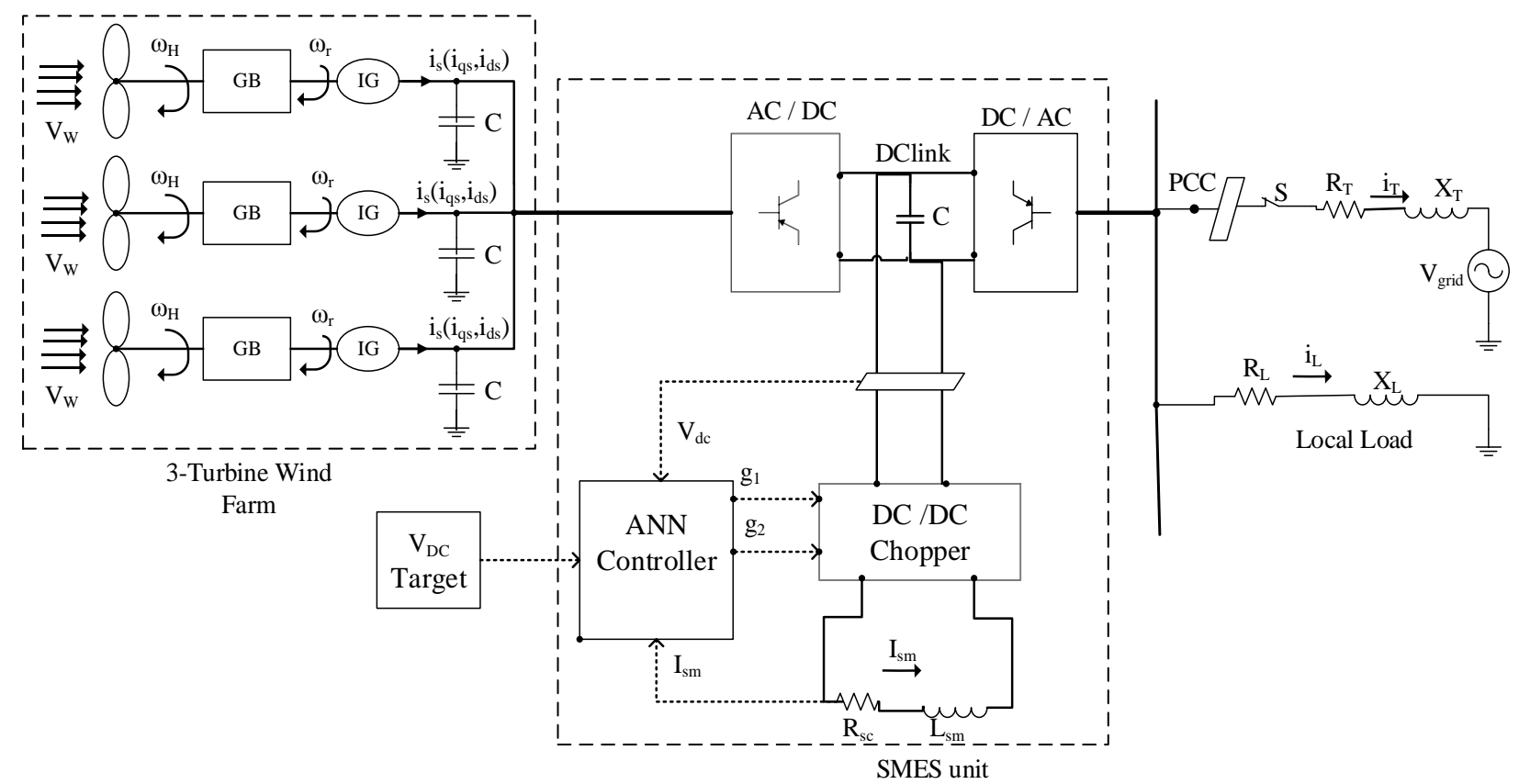

Fig. 1. Configuration of the studied WF with an SMES unit, an ANN controller, a local load, and a connected grid.

In the designed system shown in Fig. 1, the SMES unit is applied to simultaneously stabilize the voltage across the DC link $V d c$, and frequency fluctuations by varying the operating modes of the SMES unit. In this configuration, the studied system consists of the following: a wind model, a gear box (GB), an IG model, an SMES unit with an ANN controller, a local load, and an excitation capacitor bank (C). The SMES unit consist of a superconducting coil, a bi-directional current-source power converter, and an ANN controller.

\section{A. SMES System}

An SMES consists of two main parts, a bidirectional conversion system and a superconducting coil, as illustrated in Fig. 2. Firstly, the power conversion system (PCS) has two power converters, which are used to convert between alternating and direct current sides. The second part is the superconducting coil, which has an extremely low resistance. When the direct current passes through the superconducting coil, magnetic energy is stored around it [15]. This coil has the ability to keep the magnetic energy with almost no losses for a long time [16], [17]. Furthermore, a refrigeration system is always associated with an SMES to keep the superconducting coil at an extremely low temperature.

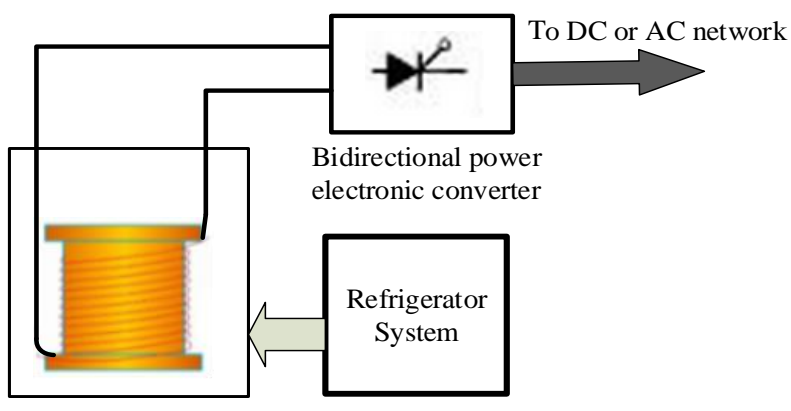

Superconducting Coil

Fig. 2. Descriptive diagram of an SMES.

The schematic diagram in Fig. 3 shows the configuration of a thyristor controlled SMES unit [18], which contains the superconducting coil and converter connected through $\mathrm{Y}-\Delta /$ Y-Y transformer.

The dc voltage $V_{s m}$ across the inductor is continuously varied between a wide range of positive and negative values. This voltage can be provided by controlling the firing angle 
of the converter. In the SMES unit, the inductor is initially charged to its rated current $I_{s m 0}$ when a small positive voltage is applied. Once it reaches its rated value, the current is constantly kept by reducing the inductor voltage to zero [19].

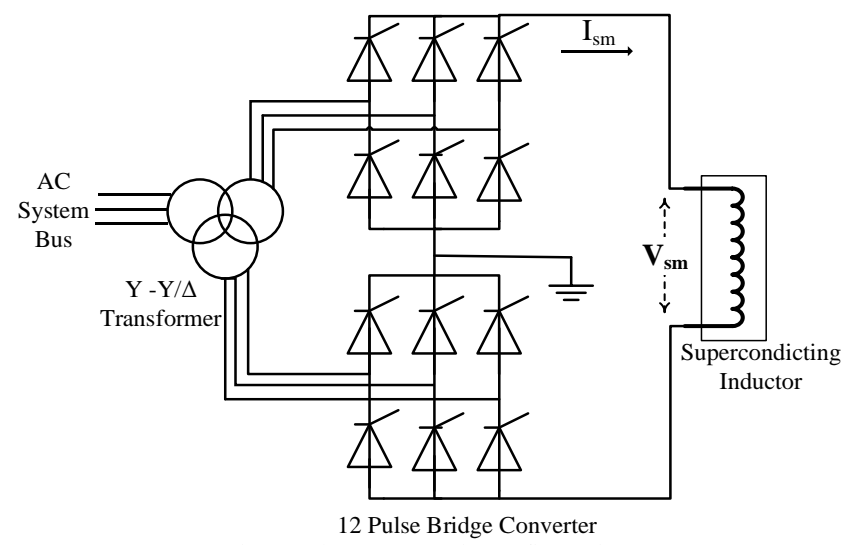

Fig. 3. The SMES unit configuration.

In order to control efficiently the power balance of the wind power generators during a dynamic period, the SMES unit is located at the generator terminal bus. The superconductive inductor coil is charged and discharged according to grid performance. Here, the dc magnetic coil is connected to the ac grid by the PCS. When this inductor is charged, the superconducting coil maintains current without any losses, and thus the energy is stored in the SMES inductance. If there are any changes in the grid power balance, the SMES changes its state to charge or discharge energy to the power grid. When the load is suddenly increased, the SMES in its discharging mode releases immediately its stored energy through the PCS as an alternating current to the grid. Whereas, if a sudden decrease in the load occurs, the superconducting coil rapidly changes to the charging mode to absorb the excess energy from the power system. The process of SMES charging is completed, when the power system returns to its steady state.

The SMES changes its state to charge, discharge or keep its stored energy depending on the dc-dc chopper mode by varying the controlling signals $\mathrm{g} 1$ and $\mathrm{g} 2$. These signals are used to control the opening and closing of the IGBT2 in the dc-dc chopper. When both g1 and g2 are 1s, the SMES is in charging mode, and when $\mathrm{g} 1=0$ and $\mathrm{g} 2=1$ the dc current continually circulates in both dc-dc chopper and the superconducting coil during the freewheeling operating mode. Whereas, when they are both 0s, the SMES acts to discharge its stored energy to the grid. Fig. 4 shows these three operating modes of the dc-dc chopper respectively [20].

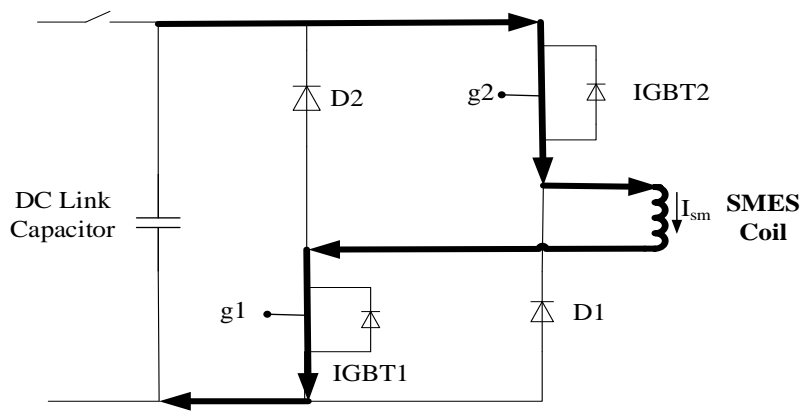

(a) Charging operation mode.

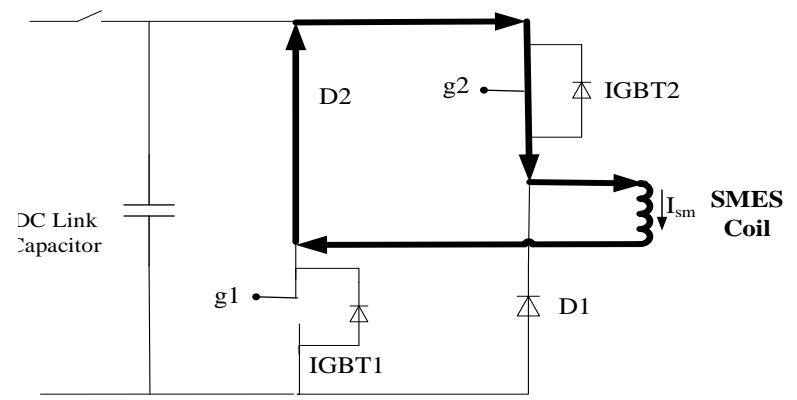

(b) Freewheeling operation mode.

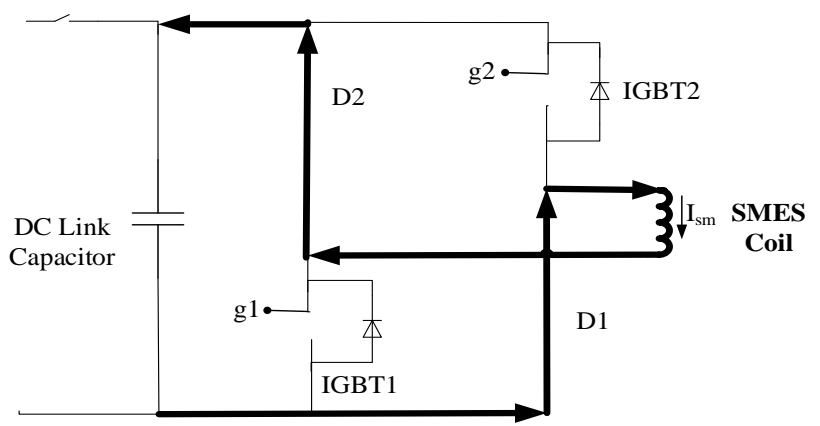

(c) Discharging operation mode.

Fig. 4. The dc-dc chopper operation modes.

In the superconducting inductor, the current and voltage are related as:

$$
I_{s m}=\frac{1}{L_{s m}} \int_{t \mathrm{O}}^{t} V_{s m} d t+I_{s m \mathrm{O}}
$$

where $I_{s m}$ is the inductor initial current. When the switching loss of the converter is ignored, the active power $\left(P_{s m}\right)$ that is absorbed or delivered by the SMES can be expressed as:

$$
P_{s m}=V_{s m} \times I_{s m}=V_{s m 0} \times I_{s m} \cos (\alpha)
$$

The power $P_{s c}$ is only a function of $\alpha$, which depends on the voltage of the superconducting coil $\left(V_{s m}\right)$. It can be positive or negative. When $V_{s m}$ is positive, the power is absorbed by the SMES unit from the power system. Conversely, if it is negative, the power is released from the SMES unit to the power system [21], [22].

The energy stored in the superconducting inductor can be expressed as:

$$
\begin{gathered}
W_{s m}=W_{s m 0}+\int_{t 0}^{t} P_{s m} d t \\
W_{s m 0}=\frac{1}{2} L_{s m} I_{s m 0}^{2}
\end{gathered}
$$

where $W_{s m 0}$ is the initial energy in the inductor. Therefore, the SMES stores a large amount of energy depending on both the current that flows through the superconducting coil and its conducting capacity.

In the system under consideration, the SMES has three 
different operating modes. First, the SMES is absorbing energy from the power system to its superconducting coil in a charging mode. Second, the SMES is in stand-by mode, also called a freewheeling mode, in which the dc current efficiently circulates in the superconducting coil in a closed loop. During this operating mode, the current is circulating for long periods of time while storing a large amount of energy with no loss because of the low resistive characteristic of the superconducting coil. Third is the discharging mode when the SMES coil discharges the stored energy into the dc-link capacitor. The fast speed of charging and discharging the SMES coil is related to its rated current. The dc-dc chopper is used to control and change between these operating modes of the SMES unit.

\section{B. The Artificial Neural Network}

The artificial neural network (ANN) as a trained control method is used to improve the dynamic response of transferring energy between the SMES and power system for rapid stabilization of voltage and frequency fluctuations that occur after system transitions and load changes.

In this research study, the ANN was trained off line at different load parameters and wind speeds through Back Propagation Algorithm (BPA) for obtaining the best value for the ANN controller parameters. In this ANN offline training there are two inputs. Firstly, the DC link voltages change due to fluctuating wind speed or swinging power loads. Secondly, the data of the voltage across the DC link that were earlier taken with using SMES unit that considered as the reference target. This voltage target is the DC link voltage that leads to stabilize the power system. Fig. 5 shows the ANN controller's inputs and the output.

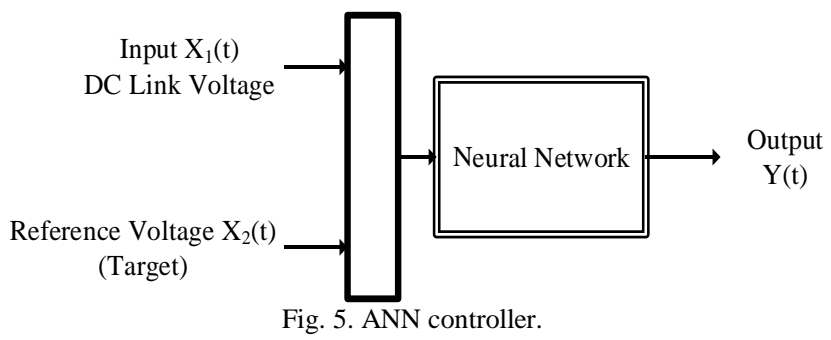

The output of the ANN controller is the predictive DC link voltage. In this study, this voltage is compared with the actual voltage across the DC link instantaneously through adaptive control method to create controlling signals ( $\mathrm{g} 1$ and g2) that control and change the operation modes of the dc-dc chopper. In this study, the neural network has been designed to predict an output series $Y(t)$ when $d$ past values of input series $X(t)$ are given. Fig. 6 shows the structure of the neural network that has two input nodes, one hidden layer and one output layer.

The back propagation rule defines how to change the weights in the artificial neural network in order to minimize the error function that is given by:

$$
E=\frac{1}{2} e^{T} e
$$

where $e$ is the error vector and $T$ is the sampling period [23]. In back propagation rule, the weights change according to the gradient descent method of optimization as:

$$
\Delta \omega_{i j}^{1}=-\mu \frac{\partial E}{\partial \omega_{i j}^{1}}
$$

where $\omega_{i j}^{1}$ is the weight of the neuron $i$ in layer $l$ connecting to the neuron $j$ in the next layer, $\mu$ is the learning rate, which corresponds to step size in the gradient-based optimization methods. In the neural network controller used in this work, $l$ can be 1,2 , or 3 . The gradient of the error function, for example, at the output layer (the third layer) is calculated as follows:

$$
\hat{S}_{J}^{3}=-e_{j} f_{j}^{3^{\prime}}
$$

Here, $f_{j}^{3^{\prime}}$ is the derivative of the activation function of the $j$ th neuron at the output layer. The gradient of energy functions for the hidden layer (e.g., the second layer) is as follows:

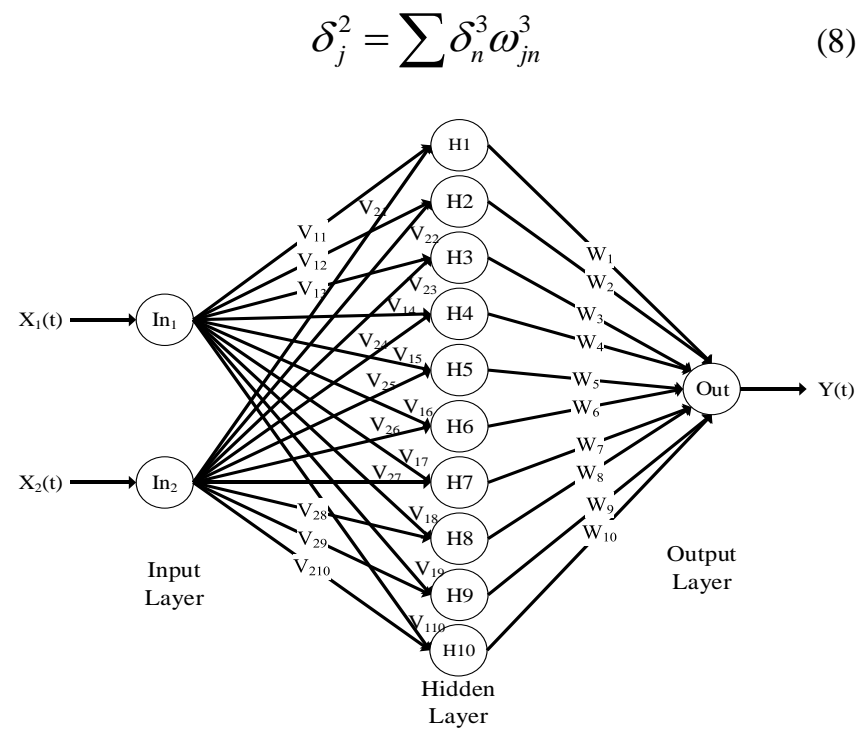

Fig. 6. Structure of neural network.

Therefore, the weights are changed according to the following rule for the hidden and output layers, respectively, as follows:

$$
\begin{aligned}
& \Delta \omega_{i j}^{2}=-\mu \delta_{j}^{2} f^{2}\left(v_{j}^{i}\right) \\
& \Delta \omega_{i j}^{3}=-\mu \delta_{j}^{3} f^{2}\left(v_{j}^{i}\right)
\end{aligned}
$$

where $\delta$ is the error gradient, $v$ is the product of weights and inputs in each layer.

The neural network controller designed and used in this work has ten neurons with two delays in the hidden layer and one neuron in the output layer. The ANN controller is trained by using back propagation algorithm, which is well explained in [23]. For training purposes, about 30000 data samples have been taken. These training data are collected from the simulation model by variation of the wind speed in the wind farm generation system. The neural network was 
continuously trained for 300 epochs to obtain the best values of weights with the highest training regression, the best validation performance, and the lowest training error.

\section{The Adaptive Control}

In this study, the artificial neural network (ANN) as a model reference with adaptive control strategy is used as a combatable controlling process. Fig. 7 shows adaptive control and ANN strategy-based SMES.

This control process begins with offline training of the Neural Network (NN). The inputs of NN are the DC link voltage that fluctuates because of wind speed changes and a voltage across the link as target voltage $(11 \mathrm{kV})$ that stabilize the power system, whereas the output of $\mathrm{NN}$ is a model reference signal $y_{m}$. In the adaptive controller, the model reference signal $y_{m}$ and voltage of the DC link in the power system $y$ are compared. Depending on the error of this comparison and the state of the superconducting coil two controlling signals $(\mathrm{g} 1, \mathrm{~g} 2)$ are generated by the controller unit. These signals are used to change the state of the $\mathrm{dc}-\mathrm{dc}$ chopper to control and adjust the operational modes of SMES unit to charge, or discharge its energy to/from power system, or to keep this energy during the continuous circulating operating mode in magnetic form "to be published" [24].

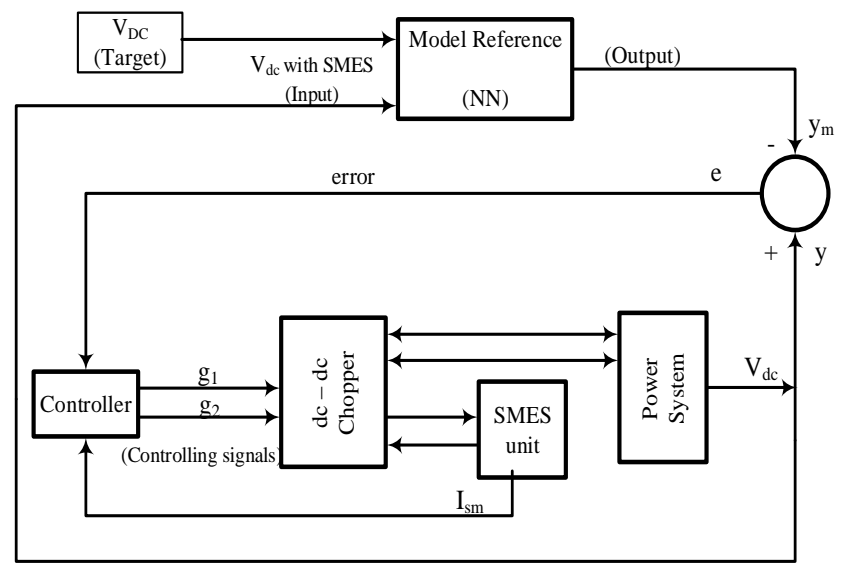

Fig. 7. The block composed of the adaptive controller and ANN based SMES

\section{The Simulations Results Under DisturbanCE CONDITIONS}

TABLE I: SMES AND THE POWER SYSTEM SPECIFICATIONS IN THE DESIGN SYSTEM

\begin{tabular}{lc}
\hline \hline SMES energy capacity $[\mathrm{MJ}]$ & 1 \\
\hdashline Rated current $[\mathrm{kA}]$ & 1 \\
\hdashline Superconducting coil inductance $[\mathrm{H}]$ & 20 \\
\hdashline DC link capacitor $[\mathrm{mF}]$ & 10 \\
\hline Nominated wind speed $[\mathrm{m} / \mathrm{s}]$ & 13 \\
\hline \hline
\end{tabular}

In this section, we demonstrate the comparative damping enhancement performance of the studied WF under disturbance of wind speed conditions. Three different power instability events applied to the proposed SMES system were simulated: voltages fluctuations in wind power generation systems, power supply frequency oscillations when rapid changes in the loads occur, and the case of production of excess power that is generated at the start of operation of the wind power generators. In these three instability events, the transient responses of the studied system with the WF only and the WF with SMES unit with an adaptive neural network controller under a ramp-wind condition are compared. All simulation results are obtained by using Matlab and Simulink. The parameter values of the SMES and the power system used during the simulation are given in Table I.

\section{A. Voltage Fluctuations}

In the designed system, a nominal wind speed $(13 \mathrm{~m} / \mathrm{s})$ was chosen to get the nominal generated power by three induction generators (IG) as a wind farm generation system. In this simulation, the wind speed was randomly changed between 8 and $13 \mathrm{~m} / \mathrm{s}$. This random change in the wind speed led to random fluctuation in the generated power amount of the wind generation, which caused voltage fluctuations in the power system. In the designed system, with these voltage fluctuations, SMES changed its operational mode by controlling the dc-dc chopper to charge or discharge its stored energy to the power system. By these operational mode changes, SMES maintained the voltage across the DC link constant at the nominal value $(11 \mathrm{KV})$. That allowed the power system to remain in the steady state. Fig. 8 shows the fluctuations in wind speed, wind generated power, voltage across the dc link capacitor, and the dc current through the SMES coil during the charging and discharging operation modes with and without using the SMES unit. It shows clearly that the stability of the voltage cross the dc link capacitor with applying the SMES was effectively improved, which led the power system to be more stable.

\section{B. Frequency Fluctuations}

In wind power systems, the random changes in wind speed affects both generation and load's frequency oscillations. The SMES unit is linked in the system under consideration assisted efficiently to reduce these instabilities in power frequency. When it charged or discharged rapidly its stored energy to the power system it well acted as a DC source. In the following simulations, the wind speed was also affected and changed in the range between 8 and $15 \mathrm{~m} / \mathrm{s}$. When the SMES unit was applied, it is controlled to change its operational modes rapidly to absorb any excess energy or to release the stored energy to the power system thus reducing the wind speed effects.

Fig. 9 shows the effect of SMES on both the wind turbine frequency and the load frequency in the system designed, with some fluctuations in wind speed. It can be clearly seen that both, the generator's and the load's frequencies, were stabilized when SMES was applied and that led to increased power system's stability.

\section{Starting Operations of Wind Power System}

WF generators at the start of their operation are generating a very high power that exceeds the nominal power of the system. Using SMES linked to WF can reduce wind power system transience and reach faster the steady-state power. It absorbs excess energy in a rapid charging process by converting this energy to magnetic form around its superconducting coil. In the following simulation, the transient responses of the system with and without SMES were compared. The system was designed to generate $(0.5$ $\mathrm{Mw})$ at a constant wind speed $(10 \mathrm{~m} / \mathrm{s})$. Fig. 10 and Fig. 11 show the simulations results of the generated power of the wind turbine, the DC link voltage and the SMES current changes with and without applying the SMES respectively. 

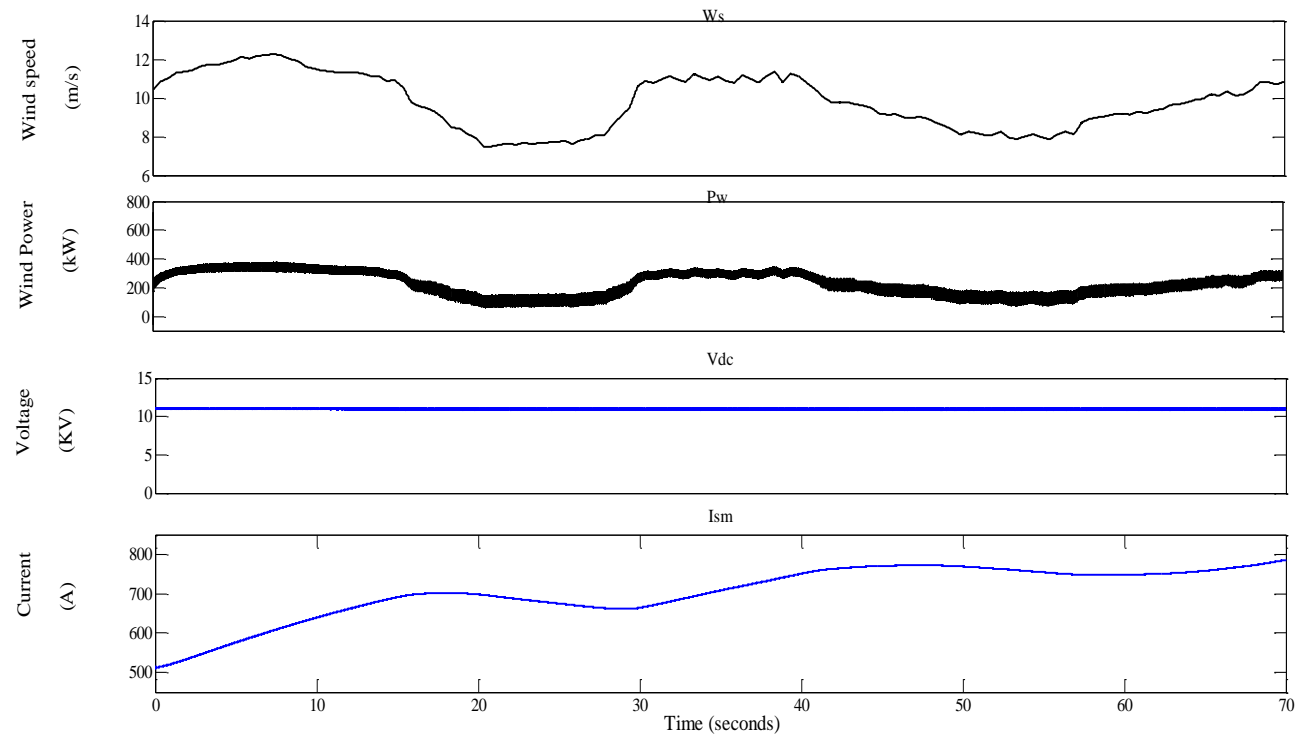

(a) With the SMES
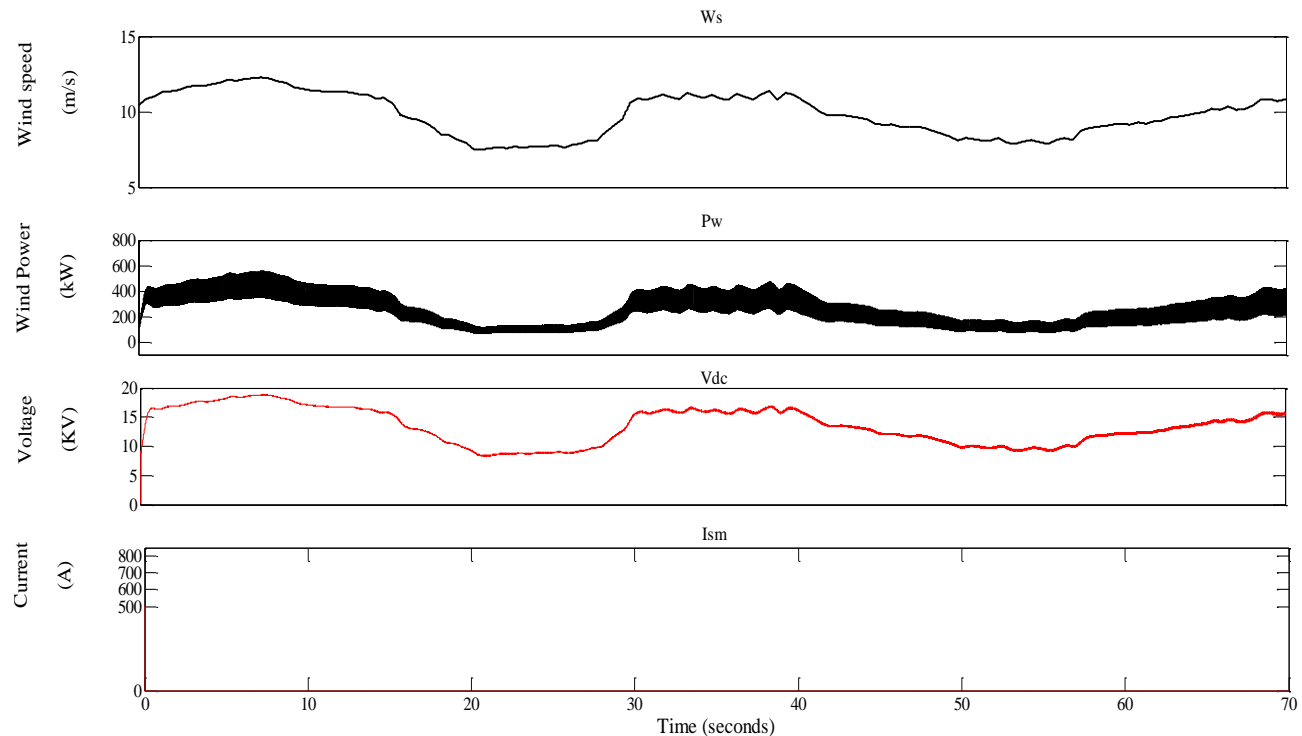

(b) Without the SMES.

Fig. 8. The simulations of voltage fluctuations.
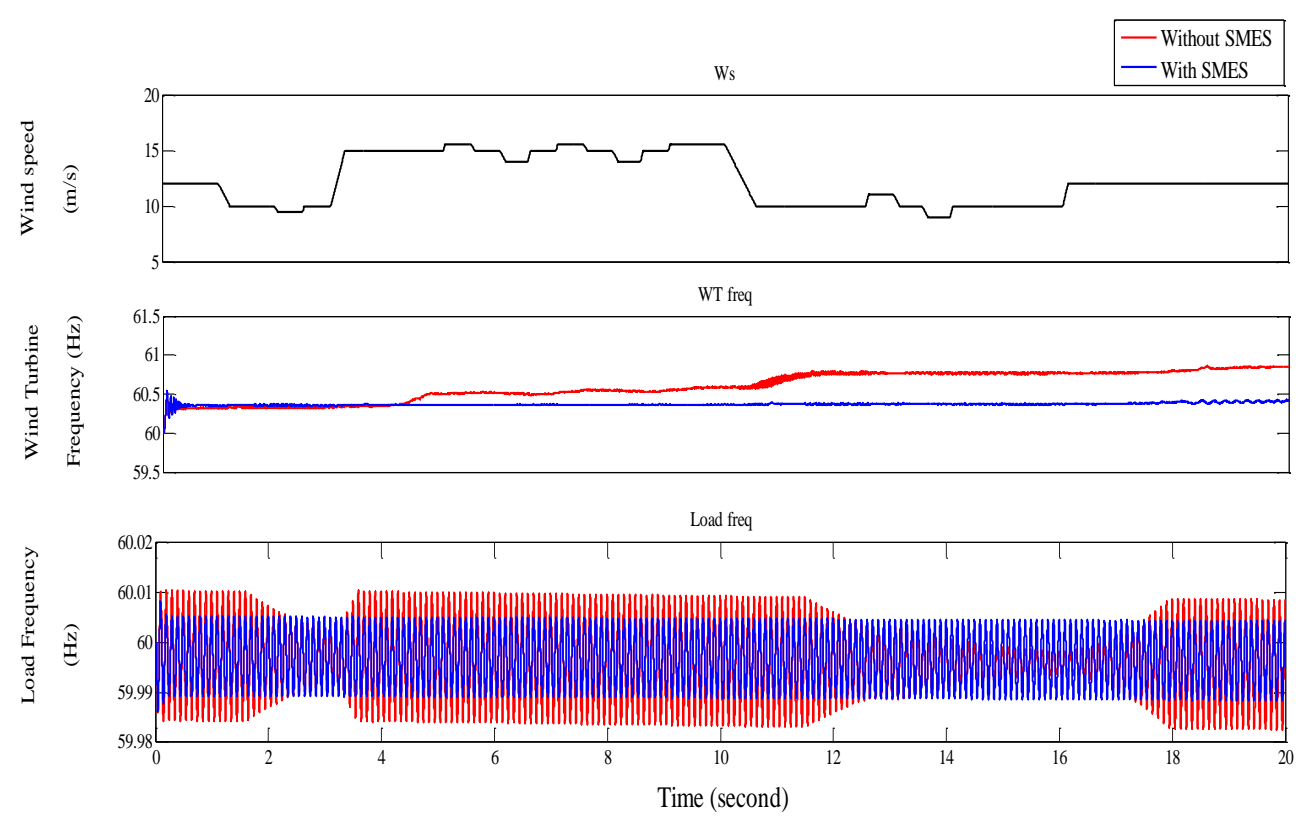

Fig. 9. The simulations of wind turbine and load frequencies with and without the SMES. 
PW

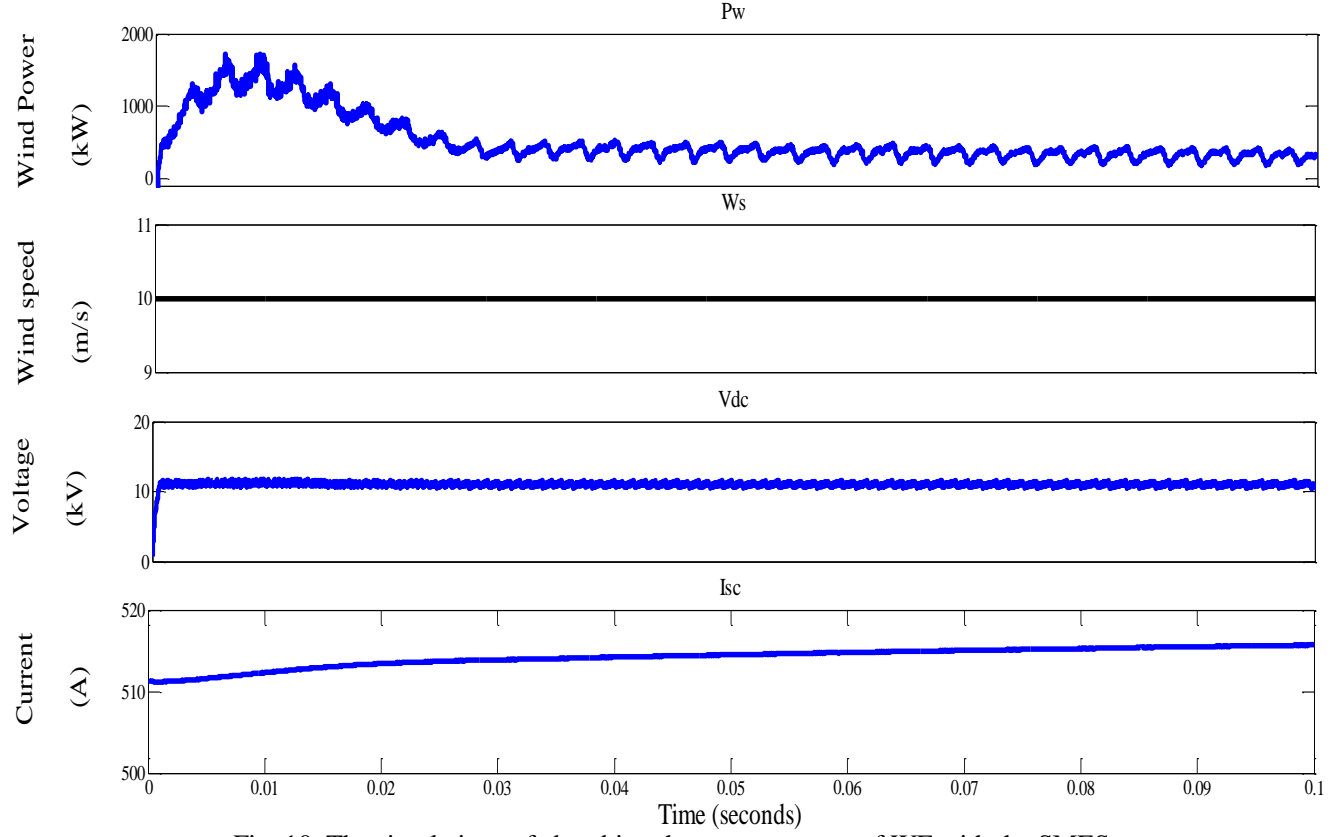

Fig. 10. The simulations of absorbing the excess energy of WF with the SMES.

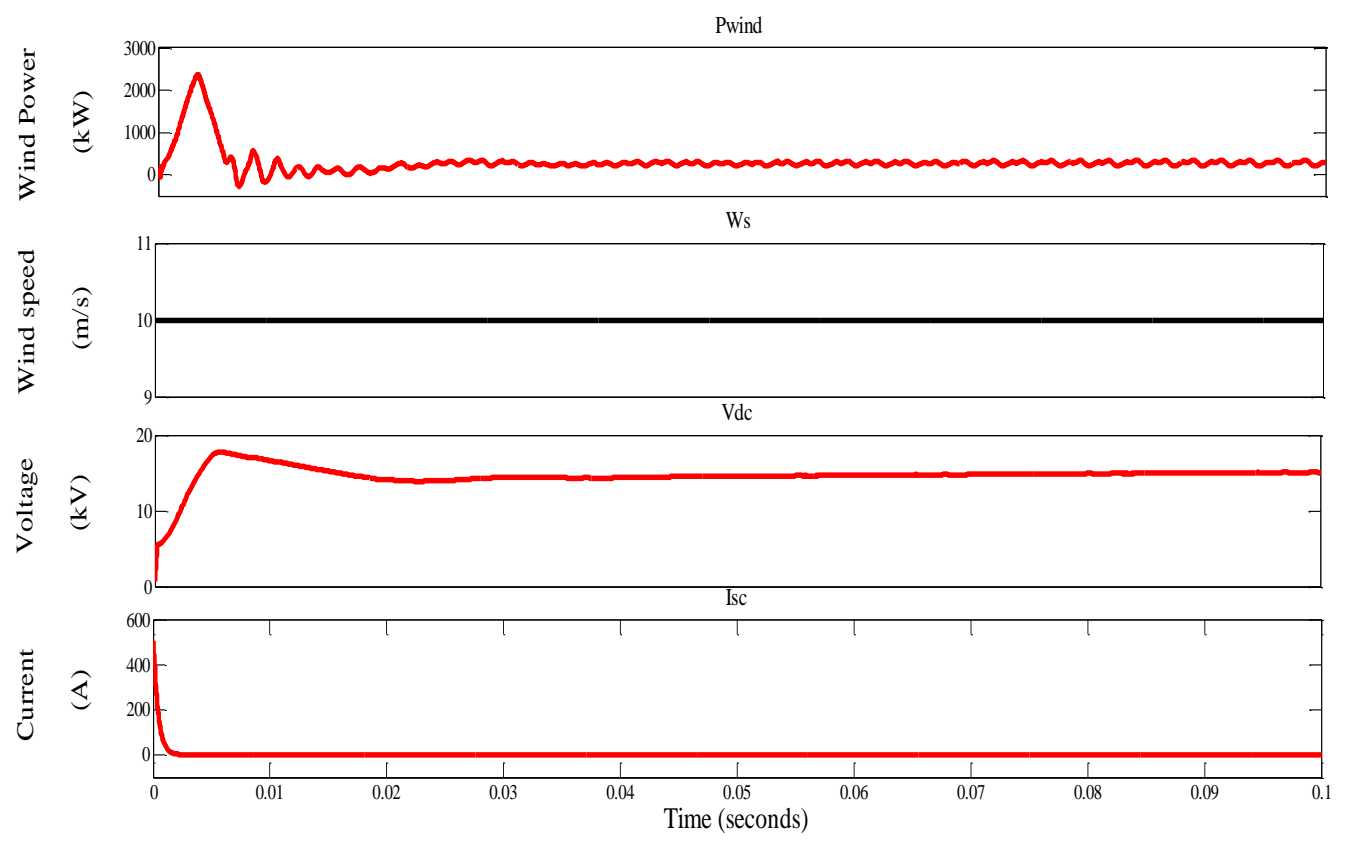

Fig. 11. The simulations of absorbing the excess energy of WF without the SMES.

\section{CONCLUSIONS}

In this paper, we have presented transient responses of a wind farm (WF) containing an effective superconducting magnetic energy storage (SMES) unit and a designed NN damping controller. To stabilize and control the fluctuation of the wind power generated due to the affected wind speed variations, we designed and studied a power conditioning system of the SMES controlled by using the artificial NN method for an independent and a simultaneous control of active and reactive power flow. From the transient simulations results, we were observed that the system frequency oscillations due to wind speed fluctuations in both generation and load areas were effectively damped out with use of the SMES unit. It has also been shown that the voltage of the DC link at the joining point of the SMES to the power system was efficiently controlled to be maintained at the nominal voltage when the SMES unit was applied. Moreover, the results show that the SMES was capable of absorbs rapidly the very high-generated energy that was produced at starting operation of wind power generates. This was achieved by transferring and charging this excess energy to be saved in magnetic form around the superconducting coil.

In this study, we conclude that the proposed ANN based SMES damping controller located as an interface device between the WF generation and grid or local load is a very effective device for stabilizing power fluctuations of a WF, while minimizing both bus-voltage and frequency oscillations of power systems simultaneously. These stabilizing and minimizing will increase the stability and enhance the overall performance of power systems.

\section{REFERENCES}

[1] S. Rahman, "Going green-the growth of renewable energy," Power and Energy Magazine, vol. 99, pp. 16-18, 2003. 
[2] L. Tsung-Ying, "Operating schedule of battery energy storage system in a time-of-use rate industrial user with wind turbine generators: A multipass iteration particle swarm optimization approach," IEEE Transactions on Energy Conversion, vol. 22, pp. 774-782, 2007.

[3] R. S. Bhatia, S. P. Jain, D. K. Jain, and B. Singh, "Battery energy storage system for power conditioning of renewable energy sources," in Proc. International Conference on Power Electronics and Drives Systems, 2005, pp. 501-506.

[4] D. J. Swider, "Compressed air energy storage in an electricity system with significant wind power generation," IEEE Transactions on Energy Conversion, vol. 22, pp. 95-102, 2007.

[5] Q. Jiang and M. F. Conlon, "The power regulation of a pwm type superconducting magnetic energy storage unit," IEEE Transactions on Energy Conversion, vol. 11, pp. 168-174, 1996.

[6] W. Li, L. Shin-Muh, and H. Ching-Lien, "Damping subsynchronous resonance using superconducting magnetic energy storage unit," IEEE Transactions on Energy Conversion, vol. 9, pp. 770-777, 1994.

[7] S. Nomura, Y. Ohata, T. Hagita, H. Tsutsui, S. Tsuji-lio, and R. Shimada, "Wind farms linked by SMES systems," IEEE Transactions on Applied Superconductivity, vol. 15, pp. 1951-1954, 2005.

[8] W. Li, C. Shiang-Shong, L. Wei-Jen, and C. Zhe, "Design of a damping controller for a SMES unit to suppress tie-line active-power fluctuations of a large-scale wind farm," in Proc. Power Systems Conference and Exposition, 2009, pp. 1-7.

[9] A. Abu-Siada, K. K. Keerthipala, and W. B. Lawrance, "Application of a superconducting magnetic energy storage unit to improve the stability performance of power systems," presented at the IEEE Canadian Conference on Electrical \& Computer Engineering, Canada 2002.

[10] M. H. Ali, B. Wu, and R. A. Dougal, "An overview of SMES applications in power and energy systems," IEEE Transactions on Sustainable Energy, vol. 1, 2010.

[11] L. Wang, S.-S. Chen, W.-J. Lee, and Z. Chen, "Design of a damping controller for a SMES unit to suppress tie-line active-powe fluctuations of a large-scale wind farm," in Proc. Power Systems Conference and Exposition, 2009, pp. 1-7.

[12] A. H. M. A. Rahim and A. M. Mohammad, "Improvement of synchronous generator damping through superconducting magnetic energy storage systems," IEEE Transactions on Energy Conversion, vol. 9, pp. 736-742, 1994.

[13] M. H. Ali, T. Murata, and J. Tamura, "A fuzzy logic-controlled superconducting magnetic energy storage for transient stability augmentation," IEEE Transactions on Control Systems Technology, vol. 15, pp. 144-150, 2007.

[14] A. Demirören, H. Zeynelgil, and S. Sengör, "The application of neural network controller to power system with SMES for transient stability enhancement," European Transactions on Electrical Power, vol. 16, pp. 629-646, 2006.

[15] R. Strzelecki and G. Benysek. (2008). Power electronics in smart electrical energy networks. [Online]. Available: http://ECU.eblib.com.au/patron/FullRecord.aspx?p=364068

[16] J. Ekanayake, N. Jenkins, K. Liyanage, J. Wu, and A. Yokoyama. (2012). Smart grid: Technology and applications. [Online]. Available: http://ECU.eblib.com.au/patron/FullRecord.aspx?p=867633

[17] J. Wen, X. J. Jian, G. J. Guo, and J. G. Zhu, "Theory and application of superconducting magnetic energy storage," in Proc. Australasian Universities Power Engineering Conferences, Melbourne, Australia, 2006.

[18] S. C. Tripathy, R. Balasubramanian, and P. S. C. Nair, "Effect of superconducting magnetic energy storage on automatic generation control considering governor deadband and boiler dynamics," IEEE Transactions on Power Systems, vol. 7, pp. 1266-1273, 1992.

[19] S. C. Tripathy, R. Balasubramanian, and P. S. C. Nair, "Adaptive automatic generation control with superconducting magnetic energy storage in power systems," IEEE Transactions on Energy Conversion, vol. 7, pp. 434-441, 1992.

[20] E. Salih, S. Lachowicz, O. Bass, and D. Habibi, "Application of a superconducting magnetic energy storage unit for power systems stability improvement," in Proc. International Conference on Green Energy, Sfax, Tunisia, 2014.

[21] H. Shayeghi, A. Jalili, and H. Shayanfar, "A robust mixed $\mathrm{h} 2 / \mathrm{h} \infty$ based lfc of a deregulated power system including SMES," Energy Conversion and Management, vol. 49, pp. 2656-2668, October 2008.
[22] J. Baba, T. Nitta, Y. Shirai, and Y. Hayashi, "Power controllable region of a power conversion system for SMES by use of a single natural commutation converter and an icb energy transfer circuit," IEEE Trans. on Applied Superconductivity, vol. 14, pp. 758-761, June 2004.

[23] N. S. S. H. L. Z. A. Demiroren, "Automatic generation control by using ANN technique," Electric Power Components and Systems, vol. 29, pp. 883-896, October 2001.

[24] E. Salih, S. Lachowicz, O. Bass, and D. Habibi, 'Superconducting magnetic energy storage unit for increasing stability of a wind power generation system," in Proc. Australasian Universities Power Engineering Conference, Perth, Australia, 2014.

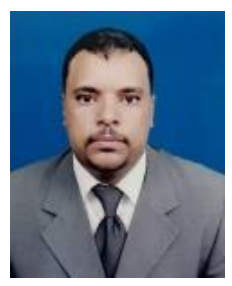

Embaiya Salih was born in Alzighan, Libya on 30 March, 1974. He received his BSc and M.Sc degrees both in electronic engineering from Sebha University, Sebha, Libya in 1997 and 2008 respectively. He had experience working in a Communication Company as an electronic engineer and as an instructor engineer at the Faculty of Engineering, Sebha University for eight years and as a lecturer assistant at the same faculty for two years. He is currently working toward his Ph.D. degree at Edith Cowan University, WA Australia under the supervision of Dr. Stefan Lachowicz and Dr. Octavian Bass.

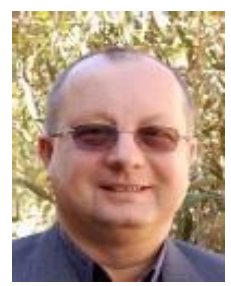

S. Lachowicz was born in Lodz, Poland, on February 22, 1959. He received his MsEE and $\mathrm{PhD}$ degrees in electronic engineering from the Technical University of Lodz, Poland, in 1981 and 1986 respectively. From 1986 until 1992 he was an assistant professor at the same university. In 1993 he joined the School of Engineering at Edith Cowan University, Perth, Western Australia where he is working as a senior lecturer. He has authored and co-authored about 80 scientific publications. His research interests include, smart energy systems, renewable energy sources, power electronics, and digital systems.

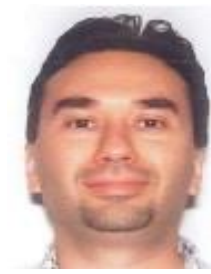

O. Bass was born in Oradea in Romania, on September 30, 1971. He graduated from the "Politehnica" University of Timisoara, Romania, in 1995 and received his $\mathrm{PhD}$ degree from the same university in 2001. His employment history includes research positions at the Budapest University of Technology and Economics, Hong Kong Polytehnic University, Hull University UK, and Utsunomiya University, Japan. He was a lecturer at James Cook University, Queensland, Australia, from 2006 to 2009 and is currently a senior lecturer at Edith Cowan University, Western Australia. His fields of interest include smart grid technologies, renewable energy resources, power electronics, nonlinear dynamics and e-learning. He has co-authored 70 professional publications.

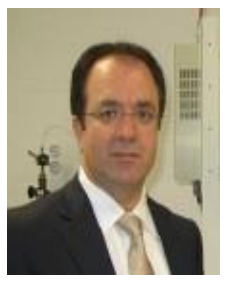

D. Habibi graduated with a bachelor of engineering (electrical) degree with first class honours from the University of Tasmania in 1989 and a PhD degree from the same university in 1994. His employment history includes Telstra Research Laboratories, Flinders University, Intelligent Pixels Inc., and Edith Cowan University, where he is currently a professor and the head of the School of Engineering. His research interests include engineering design for sustainable development, reliability and quality of service in communication systems and networks, smart energy systems, and environmental monitoring technologies. He is a fellow of Engineers Australia, electrical college board member of Engineers Australia, ITEE college board member of Engineers Australia, editor-in-chief of the Australian Journal of Electrical and Electronic Engineering, and deputy president of the Australian Council of Engineering Deans. 